\title{
Case 2 - Ovarian small cell carcinoma: a case report and review of the literature
}

\author{
Vanda Salutari $^{1}$
}

\begin{abstract}
Ovarian small cell carcinoma is a rare tumor associated with poor prognosis. Although combination chemotherapy remains the cornerstone of treatment due to the rarity of these tumors, there is no evidencebased consensus for a standard treatment, although in the majority of cases platinum-based regimens are used. A case of small cell carcinoma of the ovary, hypercalcemic-type (SCCOHT), in a 22 year-old patient is reported.
\end{abstract}

Key words: ovarian cancer, small cell carcinoma of the ovary, hypercalcemic-type, hypercalcemia

\section{Introduction}

Small cell carcinoma of the ovary is a rare histotype of ovarian cancer; hypercalcemic type (SCCOHT) is characterized by a very aggressive behavior and generally occurs in young women [1].

First described by Dickersin et al. [2] patients with small cell carcinoma of the ovary typically present with a unilateral large tumor and the majority of patients (62\%) also present with hypercalcemia [1] probably due to parathyroid hormone like proteins produced by cancer cells; for this reason calcemia and parathyroid hormone could be used as biomarkers of response to chemotherapy $[1,3,4]$.

Young et al. have presented a large series of cases (including 150 patients) describing the histologic features of this tumor type [1]; the genesis of small cell carcinoma of the ovary is unknown, in fact the tumor cells can not be classified into surface epithelium, germ cell, sex cord or neuroendocrine cells (Table 1) [5]. The differential diagnosis includes germ cells tumors, granulosa tumors, malignant lymphoma, desmoplastic small round cell tumor of the ovary, metastatic small cell carcinoma [1], in this context a very expert pathologist is crucial, due to extreme rarity of the disease. About $80 \%$ of small cell carcinomas of the ovary overexpress p53 protein, suggesting that a p53 mutation may involve in tumor genesis and progression [6], however further investigation is needed to clarify its role and prognostic significance. Optimal management of patients is not well defined; in literature several and different treatment strategies and chemotherapy are reported but in few cases due to the rareness of the disease, Harrison et al. presented a review of the management of 17 cases in a Gynecological Cancer Intergroup (GCIG) study, with poor results showed [7]. In this context there are no evidence based recommendations nor guide lines (Table 2) [1, 3, 8-14]. We present and discuss a case of SCCOHT in a young patient, as well a review of the literature about ovarian small cell tumors treatment.

\section{Case description}

On June 2014 a 22 year-old patient was admitted to the Gynecologic Emergencies for abdominal pain and volume increase in the last month. Abdominal and pelvic transvaginal ultrasound showed a right ovary solid inhomogeneous mass of $120 \times 97 \mathrm{~mm}$, and ascitic fluid.

Abdominal computed tomography (CT) scan showed a right pelvic mass of $120 \times 100 \mathrm{~mm}$, with a calcific area of $22 \mathrm{~mm}$, ascitic fluid, peritoneal irregularities and abdominal lymphadenopathies.

She underwent a planned exploratory laparoscopy with evidence of hematic abdominal ascites, a pelvic mass of $12 \mathrm{~cm}$ and pelvic peritoneal carcinosis. Therefore, patient was submitted to laparotomy, right salpingo-oophorectomy, pelvic and para-aortic lymphadenectomy, omentectomy, and peritoneal biopsies. The uterus and left ovary appeared normal so they were not removed, considering the young age of the patient. She was op-

\footnotetext{
'Gynecology Oncology Unit, Policlinico Universitario A. Gemelli, Rome, Italy.

Correspondence to:

Vanda Salutari,

Gynecology Oncology Unit, Policlinico Universitario A. Gemelli,

Largo A. Gemelli 1, 00136 Roma, Italy.

Phone: +3906 30158545 - Fax: +39 0630157241

E-mail: vanda.salutari@libero.it

CANCER BREAKING NEWS 2017;5(1):35-39

DOI: $10.19156 / \mathrm{cbn} .2017 .0038$
} 
timally debulked with no evidence of residual disease. Intraoperative pathology reported indifferantiated carcinoma of the ovary. Final pathology showed SCCOHT, with metastases to the omentum, peritoneum and pelvic and paraaortic lymph nodes, FIGO stage IIIC. Immunohistochemistry was notable for EMA, CAM5.2 e vimentin positivity, negative staining for cytokeratin 7 , cytokeratin 20, LCA, S100, TTF1, inhibin. Hystology was review and confirmed by the expert Gyneco Patologist of the Istitution. Postoperative cancer antigen (Ca)-125 was $65 \mathrm{U} / \mathrm{mL}$, lactate dehydrogenase (LDH) remained elevated at $507 \mathrm{UI} / \mathrm{L}$. Adjuvant chemotherapy was planned, consisting of cisplatin, cyclophosphamide, bleomycin (PEB) for six cycles (bleomycin was stopped after four cycles).

A chest-abdominal CT scan performed 20 days after surgery showed a diffuse peritoneal carcinosis and ascitic fluid, and Ca-125 was $214.6 \mathrm{U} / \mathrm{mL}$. After three cycles of chemotherapy, chest abdomen CT scan showed reduc- tion of peritoneal carcinosis, ascitic fluid disappeared, Ca-125 was $109 \mathrm{U} / \mathrm{mL}$ and LDH was $105 \mathrm{UI} / \mathrm{L}$.

She completed other three cycles of chemotherapy with grade 4 neutropenia; granulocyte colony-stimulating factors support was given.

After six cycles of chemotherapy patient experimented abdominal pain, volume increase and distension. Chestabdominal CT scan with contrast showed large pelvic mass, ascites, diffuse peritoneal carcinosis and mediastinal lymph nodes of $25 \mathrm{~mm}$. Ca-125 rose to $334 \mathrm{U} / \mathrm{mL}$ and LDH was $800 \mathrm{UI} / \mathrm{L}$.

The patient began treatment with weekly paclitaxel. She completed two cycles of treatment before increasing pain, ascites and hydronephrosis, and bowel subocclusion necessitated inpatient admission. The ascites continued to accumulate despite multiple paracentesis and abdominal catheter; pain and bowel occlusion worsened. She died shortly thereafter, seven months from her date of diagnosis.

Table 1. World Health Organization (WHO) histological classification of tumors of the ovary (modified from [5]).

\begin{tabular}{|c|c|}
\hline Surface epithelial-stromal tumors & Germ cell tumors \\
\hline Serous tumors & Dysgerminoma \\
\hline Mucinous tumors & Yolk sac tumor \\
\hline \multirow{4}{*}{$\begin{array}{l}\text { Endometrioid tumors including variants with squamous differentiation } \\
\text { Malignant Müllerian mixed tumor (carcinosarcoma) } \\
\text { Adenosarcoma } \\
\text { Endometrioid stromal sarcoma (low grade) } \\
\text { Undifferentiated ovarian sarcoma }\end{array}$} & Embryonal carcinoma \\
\hline & Non-gestational choriocarcinoma \\
\hline & Biphasic or triphasic teratoma \\
\hline & Immature teratoma \\
\hline Clear cell tumors & Mature teratoma \\
\hline $\begin{array}{l}\text { Transitional cell tumors } \\
\text { Malignant } \\
\text { Transitional cell carcinoma (non-Brenner type) } \\
\text { Malignant Brenner tumor } \\
\text { Borderline Brenner tumor } 9000 / 1 \\
\text { Brenner tumor } 9000 / 0\end{array}$ & $\begin{array}{l}\text { Monodermal teratoma and somatic-type tumors associated with } \\
\text { dermoid cysts } \\
\text { Thyroid tumor group } \\
\text { Struma ovarii } \\
\text { Carcinoid group } \\
\text { Neuroectodermal tumor group }\end{array}$ \\
\hline $\begin{array}{l}\text { Metaplastic variant } \\
\text { Squamous cell tumors } \\
\text { Mixed epithelial tumors (specify components) }\end{array}$ & $\begin{array}{l}\text { Primitive neuroectodermal tumor } \\
\text { Melanocytic group } \\
\text { Malignant melanoma }\end{array}$ \\
\hline Undifferentiated and unclassified tumors & \\
\hline Sex cord-stromal tumors & Small cell carcinoma, hypercalcaemic type \\
\hline Granulosa cell tumor group & Small cell carcinoma, pulmonary type \\
\hline Thecoma-fibroma group & Large cell neuroendocrine carcinoma \\
\hline Fibrosarcoma 8810/3 & Hepatoid carcinoma \\
\hline Sclerosing stromal tumor $8602 / 0$ & Primary ovarian mesothelioma \\
\hline Signet-ring stromal tumor & Wilms tumor \\
\hline Sertoli-Leydig cell tumors & Gestational choriocarcinoma \\
\hline Gynandroblastoma & Ovarian Wolffian tumor \\
\hline
\end{tabular}


Table 2. Literature review of the treatment of ovarian small cell carcinoma.

\begin{tabular}{lcl}
\hline Author & N. of patients & \multicolumn{1}{c}{ Chemotherapy regimen } \\
\hline Young et al. [1] & 150 & Vincristine, vinblastine, cyclophosphamide, doxorubicin, etoposide, and cisplatin \\
\hline Chen et al. [3] & 1 & Paclitaxel/carboplatin followed by consolidation paclitaxel \\
\hline Tewari et al. [8] & 1 & Vinblastine, cisplatin, cyclophosphamide, bleomycin, doxorubicin, and etoposide \\
\hline Benrubi et al. [9] & 1 & Cyclophosphamide, doxorubicin, cisplatin, vincristine, and etoposide \\
\hline Rana et al. [10] & 1 & Vinblastine, cisplatin, cyclophosphamide, bleomycin, doxorubicin, and etoposide \\
\hline Distelmaier et al. [11] & 11 & $\begin{array}{l}\text { Cisplatin, etoposide, ifosfamide (n=4 pts) carboplatin, etoposide, vincristine, } \\
\text { actinomycin, ifosfamide, and doxorubicin (adriamycin) (n=2 pts) } \\
\text { carboplatin/paclitaxel followed by cyclophosphamide/paclitaxel (n=1 pt) }\end{array}$ \\
\hline Dykgraaf et al. [12] & 1 & $\begin{array}{l}\text { Bleomycin, etoposide, and cisplatin } \\
\text { McCormick et al. [13] }\end{array}$ \\
\hline Nelsen et al. [14] & 1 & $\begin{array}{l}\text { Cisplatin and etoposide } \\
\text { Two cycles of intensive cyclophosphamide, etoposide, and cisplatin regimen, } \\
\text { followed by three cycles of ifosfamide, carboplatin and etoposide and an autologous } \\
\text { peripheral blood stem cell transplant }\end{array}$ \\
\hline
\end{tabular}

\section{Acknowledgments}

The authors thank Ray Hill, an independent medical writer, who provided English language editing and journal styling on behalf of HPS. This editorial assistance was funded by PharmaMar, Spain.

\section{References}

1. Young RH, Oliva E, Scully RE. Small cell carcinoma of the ovary, hypercalcemic type. A clinicopathological analysis of 150 cases. Am J Surg Pathol 1994;18(11):1102-16.

2. Dickersin GR, Kline IW, Scully RE. Small cell carcinoma of the ovary with hypercalcemia: a report of eleven cases. Cancer 1982;49(1):188-97.

3. Chen L, Dinh TA, Haque A. Small cell carcinoma of the ovary with hypercalcemia and ectopic parathyroid hormone production. Arch Pathol Lab Med 2005;129(4):531-3.

4. Matias-Guiu X, Prat J, Young RH et al. Human parathyroid hormone-related protein in ovarian small cell carcinoma. An immunohistochemical study. Cancer 1994;73(7):1878-81.

5. Tavassoli FA, Deville P (Eds). Pathology and genetics of tumors of the breast and female genital organs. Lyon, France: International Agency for Research on Cancer; 2003.

6. Seidman JD. Small cell carcinoma of the ovary of the hypercalcemic type: p53 protein accumulation and clinicopathologic features. Gynecol Oncol 1995;59(2):283-7.

7. Harrison ML, Hoskins P, du Bois A et al. Small cell of the ovary, hypercalcemic type - analysis of combined experience and recommendation for management. A GCIG study. Gynecol Oncol 2006;100(2):233-8.

8. Tewari K, Brewer C, Cappuccini F et al. Advanced-stage small cell carcinoma of the ovary in pregnancy: long-term

\section{Conflicts of Interest}

The Authors declare there are no conflicts of interest in relation to this article.

survival after surgical debulking and multiagent chemotherapy. Gynecol Oncol 1997;66(3):531-4.

9. Benrubi GI, Pitel P, Lammert N. Small cell carcinoma of the ovary with hypercalcemia responsive to sequencing chemotherapy. South Med J 1993;86(2):247-8.

10. Rana S, Warren BK, Yamada SD. Stage IIIC small cell carcinoma of the ovary: survival with conservative surgery and chemotherapy. Obstet Gynecol 2004;103(5 Pt 2):1120-3.

11. Distelmaier F, Calaminus G, Harms D et al. Ovarian small cell carcinoma of the hypercalcemic type in children and adolescents: a prognostically unfavorable but curable disease. Cancer 2006;107(9):2298-306.

12. Dykgraaf RH, de Jong D, van Veen $M$ et al. Clinical management of ovarian small-cell carcinoma of the hypercalcemic type: a proposal for conservative surgery in an advanced stage of disease. Int J Gynecol Cancer 2009; 19(3):348-53.

13. McCormick TC, Muffly T, Lu G et al. Aggressive small cell carcinoma of the ovary, hypercalcemic type with hypercalcemia in pregnancy, treated with conservative surgery and chemotherapy. Int J Gynecol Cancer 2009;19(8):1339-41.

14. Nelsen LL, Muirhead DM, Bell MC. Ovarian small cell carcinoma, hypercalcemic type exhibiting a response to highdose chemotherapy. S D Med 2010;63(11):375-7. 


\section{Commentary}

The case presented by Vanda Salutari refers to a young patient with a stage IIIC ovarian small cell carcinoma (SCCO) of hypercalcemic type (SCCOHT). Despite an aggressive complete surgery and chemotherapy based on an etoposide and cisplatin association, the disease relapsed shortly after the beginning of the therapy and the patient died rapidly.

These tumors are highly undifferentiated, and recent data suggest they may simply be an ovarian variant of malignant rhabdoid tumors [1, 2]. Mutations in the SWItch/Sucrose Non Fermentable (SWI/ $S N F)$ chromatin-remodeling gene, SMARCA4, have now been shown to be a frequent event occurring in $76 \%$ to $100 \%$ of SCCOHT tumors [3-5]. Germline mutations in SMARCA4 or SMARCB1 were already known to predispose to the development of pediatric tumors, namely atypical teratoid/rhabdoid tumors [6, 7]. SMARCA4 immunohistochemistry is highly sensitive and specific for a diagnosis of SCCOHT (loss of SMARCA4 protein expression [BRG1]) and is now of clinical utility in the differential diagnosis of poorly differentiated ovarian tumors [8].

Prognosis is poor, with only $30 \%$ to $40 \%$ of patients achieving long-term survival with standard treatment. There is no international consensus regarding the optimal treatment of SCCO, and a multimodal approach including chemotherapy, radical surgery and possibly radiotherapy is often proposed. However, no randomized studies have been conducted and the available published data are composed of case reports or small retrospective series with very heterogeneous management strategies.

To optimize the practical use of anticancer chemotherapy in these young patients with initially good tumor response, some groups have opted for an aggressive strategy with extensive surgery to lower the tumor burden on the one hand, and dose intensive chemotherapy to circumvent cell mutations. The only prospective clinical trial reported in SCCOHTs was a prospective trial testing combination intensive therapy for stage-I to IV tumors [9]. Patients received multimodality therapy with aggressive debulking surgery, chemotherapy with a platinum etoposide-based regimen (PAVEP, cisplatin, doxorubicin [adriamycin], etoposide [VP-16] and cyclophosphamide), and one cycle of high-dose consolidation chemotherapy followed by autologous stem cell support in case of complete response. Eighteen patients among 27 achieved a complete remission, and 10 proceeded to high-dose chemotherapy with stem cell support. The only long-term survivors had complete surgical resection. This procedure induced an encouraging 3-year survival rate of $49 \%$ for the entire population. This study also used neoadjuvant chemotherapy in a small number of cases, who went on to undergo delayed primary surgery. In a review of all published and a series of unpublished 290 SCCOHT cases with collected information on possible prognostic factors, high-dose chemotherapy with autologous stem cell rescue is a positive prognostic factor [10].

Even with intensive regimens and despite frequent initial responses to chemotherapy, relapses are frequent and tend to be refractory to second-line chemotherapy. The management of relapsed disease is often very challenging, and prolonged remissions are never achieved, with second-line chemotherapy regimens usually used in small cell lung carcinomas. A number of schedules have been reported, including the combination of cyclophosphamide, doxorubicin, and vincristine. There are anecdotal reports on carboplatin and paclitaxel, including dose-dense regimes, and topotecan has also shown some modest activity, as in small cell lung cancers. To date, no targeted therapies have been tested in SCCO. Second-line treatment is likely to achieve short remission rates, and beyond that, patients should be considered for phase-I trials if they remain of good performance status. The future probably requires a better understanding of the molecular drivers.

In conclusion, all suspected cases should benefit from a review by an expert pathologist and be discussed in a specialized tumor board. Optimal treatment with a multimodal approach including chemotherapy, radical surgery, high dose chemotherapy and radiotherapy has to be discussed. Efforts should be made to treat patients in a more homogeneous way through national and international networks [11]. 


\section{References}

1. Kupryjanczyk J, Dansonka-Mieszkowska A, Moes-Sosnowska J et al. Ovarian small cell carcinoma of hypercalcemic type - evidence of germline origin and SMARCA4 gene inactivation. a pilot study. Pol J Pathol 2013;64(4):238-46.

2. Foulkes WD, Clarke BA, Hasselblatt M et al. No small surprise - small cell carcinoma of the ovary, hypercalcaemic type, is a malignant rhabdoid tumour. J Pathol 2014;233(3):209-14.

3. Jelinic P, Mueller JJ, Olvera N et al. Recurrent SMARCA4 mutations in small cell carcinoma of the ovary. Nat Genet 2014;46(5):424-6.

4. Ramos P, Karnezis AN, Craig DW et al. Small cell carcinoma of the ovary, hypercalcemic type, displays frequent inactivating germline and somatic mutations in SMARCA4. Nat Genet 2014;46(5):427-9.

5. Witkowski L, Carrot-Zhang J, Albrecht $\mathrm{S}$ et al. Germline and somatic SMARCA4 mutations characterize small cell carcinoma of the ovary, hypercalcemic type. Nat Genet 2014;46(5):438-43.

6. Hasselblatt M, Gesk S, Oyen F et al. Nonsense mutation and inactivation of SMARCA4 (BRG1) in an atypical teratoid/ rhabdoid tumor showing retained SMARCB1 (INI1) expression. Am J Surg Pathol 2011;35(6):933-5.
7. Schneppenheim R, Fruhwald MC, Gesk S et al. Germline nonsense mutation and somatic inactivation of SMARCA4/ BRG1 in a family with rhabdoid tumor predisposition syndrome. Am J Hum Genet 2010;86(2):279-84.

8. Karanian-Philippe M, Velasco V, Longy M et al. SMARCA4 (BRG1) loss of expression is a useful marker for the diagnosis of ovarian small cell carcinoma of the hypercalcemic type (ovarian rhabdoid tumor): a comprehensive analysis of 116 rare gynecologic tumors, 9 soft tissue tumors, and 9 melanomas. Am J Surg Pathol 2015;39(9):1197-205.

9. Pautier P, Ribrag V, Duvillard P et al. Results of a prospective dose-intensive regimen in 27 patients with small cell carcinoma of the ovary of the hypercalcemic type. Ann Oncol 2007;18(12):1985-9.

10. Witkowski L, Goudie C, Ramos P et al. The influence of clinical and genetic factors on patient outcome in small cell carcinoma of the ovary, hypercalcemic type. Gynecol Oncol 2016;141(3):454-60.

11. Reed NS, Pautier P, Avall-Lundqvist E et al. Gynecologic Cancer InterGroup (GCIG) consensus review for ovarian small cell cancers. Int J Gynecol Cancer 2014;24(9 Suppl 3): S30-4. 